\title{
Localization of Neuroendocrine Functions Within the Hypothalamus
}

\author{
LEE L. BERNARDIS
}

SUMMARY: The results of lesion, stimulation, deafferentation, implantation and transplantation stadies employed in the identification of hypophysiotrophic control areas in the hypothalamus to date suggest the following probable locations: corticotropic releasing factor ( $C R F$ ) is formed in a diffuse area along the base of the median eminence, if not the base of the entire hypothalamus. Follicle stimulating hormone releasing factor (FSHRF) is elaborated in the paraventricular-suprachiasmatic areas bat its cyclic control may reside in the anterior hypothalamic area. Lateinizing hormone $(\mathrm{LH})$ is controlled by lateinizing hormone releasing

RÉSUMÉ: Les résultats d'études employant lésions, stimulation, déafférentation, implantation et transplantation pour recherche de régions de contrôle hypophysiotrophiques à l'hypothalamus jusqu'a présent indiquent les probables sites suivants: CRF provient d'une région diffuse à la base de l'éminence médiane, sinon la base de l'hypothalamus entier. FSHRF est formé aux régions paraventriculaires et suprachiasmatiques, mais son contrôle cyclique peut être fonction de la région hypothalamique antérieure. $L H$ est sous contrôle de $L H R F$, ce dernier étant factor (LHRF) formed in the suprachiasmatic area: its cyclic control may be in the preoptic area. Prolactin is controlled by prolactin inhibiting factor (PIF) localized in a diffuse area comprising the ventromedial, dorsomedial, arcuate and paraventricular nuclei. The hypothalamic area involved in thyroid control is also rather large, since thyrotropin stimulating hormone releasing factor (TSHRF) has been found in an area including the supraoptic and chiasmatic nuclei. Growth hormone releasing factor (GHRF) is elaborated in a rather narrow zone, the ventromedial hypothalamic nuclei.

dérivé de la région suprachiasmatique, tandis que son contrôle cyclique est de la région péoptique. Prolactin est sous contrôle de PIF, associé à une région diffuse constituée des noyaux ventromédial, dorsomédial, arcué et paraventriculaire. Le site de contrôle hypothalamique de fonction thyroïdienne est aussi plutôt vaste, TSHRF ayant été identifié à une région incluant noyaux supraprique et chiasmatique. GHRF provient d'une région plutôt restreinte, soit du noyau hypothalamique ventromédial.

From the Department of Surgery. State University of New York at Buffalo. Buffalo. New York.

Reprint Address: Dr. Lee L. Bernardis. Dept. of Surgery. State University of New York at Buffalo. Buffalo. New York.
Hypothalamic Localization of Corticotropic Releasing Factor (CRF)

It has been known for many years that an increase in pituitary-adrenal activity occurs in many mammalian species including man, after exposure to stress. The fact that stimuli such as fear, anger, pain, intense light and sound can activate the pituitary-adrenal axis has been taken to indicate the participation of the central nervous system Fortier (1952).

The earliest experimental evidence for the involvement of the hypothalamus in the activation of the pituitary-adrenal system comes from DeGroot and Harris (1950). They observed that electrolytic lesions in the zona tuberalis of the rabbit abolished the lymphopenia that normally follows emotional stress. Similar lesions in the pituitary did not have this effect.

In the mid-fifties, Saffran and Schally (1955) discovered the hypothalamic factor stimulating ACTH release - Corticotropin Releasing Factor or CRF. This was the first releasing factor to be discovered. Undoubtedly, this finding gave new impetus to experimentation and elucidation of the role of the central nervous system (CNS) in the control of ACTH.

In an attempt to define the hypothalamic area involved in CRF release under stress, Brodish divided the median eminence (ME) of the rat into four zones in the antero-posterior direction and electrolytically destroyed each zone alone or in combination with one or more other zone. The response to ether, Brodish (1963), and surgical stress, Brodish (1964), were examined. Lesions in all four areas did not prevent, but only 
delayed, ACTH secretion, and the effect was proportional to lesion size.

In a study designed to clarify the origins of various hypothalamic releasing factors, Mess et al (1967), (1970) placed four different types of lesions in the hypothalamus and the $M E$, respectively, and used the unified methods described by Fraschini, Motta and Martini (1966) and Mess et al. (1970) to assess the content of various releasing factors in $\mathrm{ME}$ extracts of the lesioned animals. Five days after the placement of the hypothalamic lesion, CRF content was not reduced after lesions in the paraventricular (PVN), suprachiasmatic $(\mathrm{SCH})$ nuclei or the arcuate-ventromedial (arcuateVMN) areas. It was moderately increased. The authors believe the hypothalamic structures manufacturing CRF have a wide distribution and possibly non-destroyed tissue can rapidly compensate for the loss of the destroyed areas.

Mess and his co-workers (1967, 1970) have other ideas about this area. i.e. the presence of hypothalamic principles in the ME does not prove that they are synthesized in this region. The ME might be considered only as a storage site for the hypothalamic releasing and inhibiting factors. Further, the hypothalamic humors might not be formed completely in the various hypothalamic nuclei but rather require some final modification at the level of the $\mathrm{ME}$ in order to become fully active. Finally, they suggested that the various factors might be transported from their formation sites along different pathways. This would lead to a separation of the different factors, perhaps at the level of the ME. Indeed, it has been reported that the $\mathrm{ME}$ may be subdivided into various regions according to vascular distribution, Adams, Daniel and Prichard (1966), Mess et al (1970).

The definition by Halasz et al (1962), (1965), of the Hypophysiotrophic Area (HTA) of the hypothalamus suggested that an area outside the ME might be involved in CRF formation. Hypophysectomized rats with pituitary grafts in the
HTA showed good maintenance of adrenal lipid histology, adrenal weight, and adrenal venous blood corticosterone content. Grafts outside the HTA caused severe adrenal atrophy.

Although these two circumscribed areas of the hypothalamus - the HTA and the ME - containing neurons synthesizing and releasing CRF were clearly identified, other questions concerning the central nervous control of CRF arose. One was the possible requirement of nervous impulses from other parts of the hypothalamus and from other parts of the CNS for the production and release of CRF at base line levels. Again, Halasz et al (1967) reported findings indicating that neural impulses need not reach the HTA to bring about release of CRF. With a special knife that now bears his name, Halasz produced cuts in various positions and of various lengths to partially or completely isolate or "deafferentate" the HTA. After total deafferentation of this area, corticosterone levels in the plasma and the adrenal gland, and pituitary ACTH content were normal or even somewhat higher than in appropriate controls. It was concluded that the HTA is capable of producing CRF without afferent connections.

Since adrenocortical secretions show a definite diurnal rhythm Critchlow (1963), one might suspect this to be due to a similar rhythm of the hypothalamic principle that "drives" ACTH. Not only does plasma corticosterone in the rat show a diurnal rhythm, but so does CRF. The levels of the latter peak at 1800 hours and have their nadir at 0800 hours. Adrenalectomy and thus the absence of corticosterone feedback does not interrupt the diurnal CRF rhythm, which suggests that the latter is of CNS origin and independent of long-loop feedback, Hiroshige and Sato (1970), Hiroshige and Sakakura (1971). This was further supported by Halasz et al (1967), who demonstrated that pathways responsible for the maintenance of the ACTH rhythm enter the HTA anteriorly since only frontal cuts interfered with the diurnal fluctuations of ACTH.
The connections could be the corticohypothalamic tract, Cajal (1911), and/or the fornix, since sections of the latter have been shown to abolish the diurnal rhythm of plasma corticosterone in the rat, Moberg, Scapagnini, DeGroot and Ganong (1971).

While long-loop feedback control of CRF appears unlikely, evidence for a short-loop feedback has been forthcoming recently. Seiden and Brodish (1972) found undisturbed diurnal variations of hypothalamic CRF in hypophysectomized rats parallel to the CRF fluctuations of intact animals. The elevated CRF levels in these animals were not altered by adrenalectomy, and the authors took their finding in the hypophysectomized - Adrenalectomized rats to indicate that a shortloop feed-back does exist and allows pituitary ACTH to regulate hypothalamic CRF. The levels of the latter were, however, altered by the injection of ACTH, Seiden and Brodish, (1971).

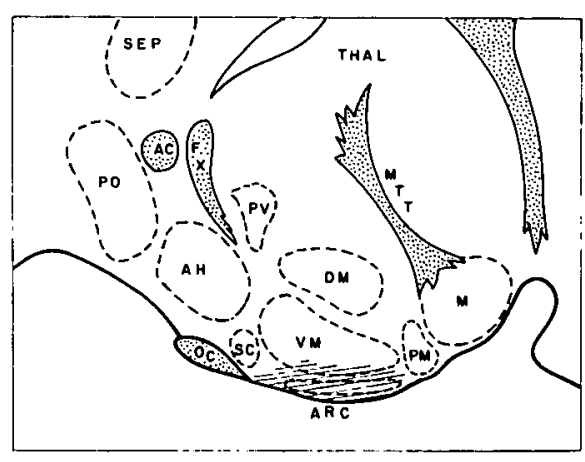

Figure I-Diagrammatic representation of sagittal section through the hypothalamus illustrating the main fiber tracts (stippled areas) and some of the larger nuclei (dashed lines). The area included within the horizontal lines is the area that has been implicated in CRF formation.

$\mathrm{AC}$-anterior commissure

AH -anterior hypothalamic area

ARC -arcuate nucleus

DM -dorsomedial nucleus

FX -fornix

M -mammillary nuclear complex

MTT -Mammillo-thalamic tract

OC -optic chiasma

PM -premammillary nucleus

PV - paraventricular nucleus

SC - suprachiasmatic nucleus

SEP - septal nuclear complex

THAL_thalamus 
In conclusion, it must be stated that the hypothalamic area subserving CRF formation is a diffusely distributed region along the base of the hypothalamus (Fig. 1). Since stress is such a non-specific entity it is perhaps well from a teleological viewpoint that the central nervous machinery required to cope with it is so diffuse.

II. Hypothalamic Localization of Follicle Stimulating Hormone-Releasing Factor (FSH-RF)

Like other processes, the functions of the pituitary control of gonadotrophic events are influenced by both external and internal signals. Since the pioneer work of Marshall (1936) it has appeared likely that exteroceptive stimuli are conveyed to the pituitary by the mediation of the hypothalamus. Similarly, interoceptive signals including the sex hormones reach the pituitary via the hypothalamus, and thereby contribute to the regulation of gonadotrophic activity of the pituitary.

Early evidence for a possible hypothalamic involvement in the control of sexual functions was provided by Aschner (1912) who showed that hypophysectomy did not always produce sex organ atrophy but injury to the hypothalamus assured it. Regulation of the gonadotropins by gonadal hormones was suggested by Hohlweg and Junkmann, (1932) who thought that this regulation was brought about by an action of sex hormones on a hypothetical "Sexualzentrum'.

The earliest direct proof for a localization of gonadotrophin control by the hypothalamus comes from Harris (1937), who found ovulation in the rabbit following electrical stimulation of the tuber cinereum and the preoptic region. Much of the recent knowledge of the hypothalamic control of Follicle Stimulating Hormone (FSH) secretion comes from Flérko's laboratory at Pecs, Hungary. The assumption that nervous elements localized in the anterior hypothalamus play an essential part in the mechanisms by which the rise of circulating estrogen levels inhibit pituitary FSH secretion has gained support from several findings. For instance, inhibition of follicle development and consequent corpora lutea (CL) formation in infantile rats precipitated by estrogen administration could be attenuated by destruction of an area between the optic chiasm and the PVN, Flérko and Bardos, (1956), (1961), Flérko (1957a).

In another study, Flérko based his experimental design on the fact that the estrogen production of an intact rat parabiotically united with a spayed partner is greatly enhanced by the high FSH output of the spayed animal's pituitary. This is well reflected in the uterine weight (133 $\mathrm{mg}$ ) of parabiosed rats and is in striking contrast to the uterine weight ( 26 $\mathrm{mg}$ ) of intact rats of a similar age. In such an experimental system the injection of $1 \mathrm{~kg}$ of estradiol/day/rat in the spayed partner results in a regression of the uterine weight to $39 \mathrm{mg}$ indicating a suppression of FSH in the pituitary of the spayed partner. Placement of electrolytic lesions between the optic chiasm and the PVN in the spayed partner, however, results in a uterine weight of $76 \mathrm{mg}$, more than double that in the same experimental model without the hypothalamic lesions, and despite the same amount of injected estradiol. Evidently, rats with AHAPVN lesions show less FSH inhibition after estrogen administration than non-lesioned rats. It was concluded that the anterior hypothalamus contains nervous elements that are sensitive to circulating estrogen and are indispensable to the mechanism by which FSH secretion of the anterior pituitary is inhibited by a slight elevation of circulating estrogen under physiological conditions, Flérko (1956) (1957b).

In order to limit more precisely the area responsible for FSH control, Mess et al (1967) (1970) produced lesions in the PVN, $\mathrm{SCH}$, ArcuateVMN and the ME. The content of FSH-RF, the releasing factor for FSH that had been described by Igarashi and McCann (1964) within the hypothalamic extracts, was reduced only after lesions in the PVN region. The implantation of cycloheximide, an inhibitor of protein synthesis, into the PVN resulted in a decreased amount of FSH-RF in the $\mathrm{ME}$ and a reduced content of pituitary FSH stores, Zanisi and Martini (1969). It is noteworthy that neither LH-RF in the hypothalamus, nor LH (Luteinizing Hormone) in the pituitaries of rats so treated showed changes. This was taken as evidence that blockade of protein synthesis in the area of the PVN inhibits FSH-RF but not LH-RF synthesis, and that FSH-RF production occurs in the PVN.

The role of the HTA in the cyclic secretion of FSH was investigated by Halasz and Gorski (1967). Ovarian compensatory hypertrophy failed to occur in rats bearing a frontal cut that separated the anterior hypothalamic area from the HTA. This indicated that neural structures responsible for the enhanced FSH secretion after unilateral ovariectomy are located outside the HTA, likely in the anterior hypothalamic area.

In conclusion, the hypothalamic area involved in the elaboration of the hypophysiotropic factor controlling Follicle Stimulating Hormone, FSH-RF or FRF, is located in the narrow region comprising the PVN and the area between the latter and the optic chiasma (Fig. 2).

\section{Hypothalamic Synthesis of Luteinizing Hormone-Releasing Fac- tor $(L H-R F)$}

The earliest experimental evidence implicating the hypothalamus in the release of $\mathrm{LH}$ and thus ovulation, comes from the electrical

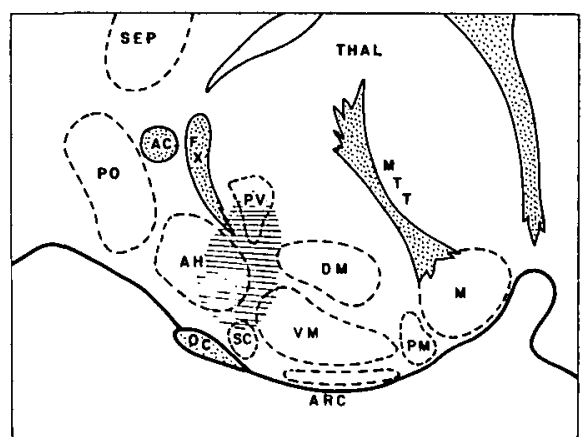

Figure 2-Diagrammatic representation of sagittal section through the hypothalamus. The area included within the horizontal lines is that area which has been involved in the elaboration of FSH-RF. The abbreviations are as in Figure 1. 
stiumulation studies of the rabbit brain by Harris (1937). Ten years later, Harris (1948) also succeeded in producing ovulation in the rabbit by electrical stimulation of the tuber cinereum that failed to cause sufficient $\mathrm{LH}$ release when applied directly to the pituitary itself. Confirming the stimulation data by electrolytic lesion experiments, Sawyer (1959) showed that loci of destruction in the "basal tuberal area" resulted in a block of coitus-induced ovulation.

Much of the credit for the work on the clarification of the hypothalamic control of $\mathrm{LH}$ goes to McCann, Taleisnik and Friedman (1960), McCann and Friedman (1960). Using the Parlow ovarian ascorbic acid depletion (OAAD) test for $\mathrm{LH}$, which is based on a drop of ovarian ascorbic acid following the administration of minute amounts of $\mathrm{LH}$ in immature-gonadotrophintreated rats, they found that stalk-median eminence extracts (SME) were capable of depleting ovarian ascorbic acid. No such effect was observed following injection into hypophysectomized rats, thus excluding a contamination with LH but not SME activity. The substance having this effect was termed Luteinizing Hormone Releasing Factor or LH-RF McCann et al (1960). After infusion of SME into the pituitary, ovulation was observed; this was not the case after systemic administration, Nikitovitch-Winer (1962).

As with other hypothalamichypophysiotrophic principles, it was of interest to identify the nervous connections involved in $\mathrm{LH}$ release. Halasz and Gorski (1967) noted that rats with cuts between the PO area and the HTA did not ovulate. The effective cuts were $1.5 \mathrm{~mm}$ from the midline and extended from the base of the brain to the level of the PVN. It was concluded that afferent connections are essential for ovulation and that they enter the HTA from rostrad. Subsequent studies by Koves and Halasz (1970) indicated that the neurogenic stimulus triggering ovulation arises, at least in part, from the preoptic-anterior hypothalamic area (PO-AHA), and that only one half of the preoptic- tuberal pathway is sufficient to induce ovulation.

The current concept is that neurons in the HTA, probably neurosecretory in nature, constitute one part of the LH control system. This part might stimulate continuous production and release of $\mathrm{LH}$ at a basal level that is necessary to maintain estrogen secretion. This tonic aspect of LH secretion is likely subserved by the HTA but is supervised by a second part of the LH control system. The latter is located in other parts of the hypothalamus, likely the PO-AHA and/or in other parts of the limbic system. This second part of the LH control system is part of a neuroendocrine control mechanism that has been termed "Release Regulating System" or "RRS" and is by definition ". . . everything outside the confines of the HTA and concerned in the nervous control of anterior pituitary functions. . ." Szentagothai, Flérko, Mess and Halasz (1968).

In their comprehensive study in the localization of hypothalamic releasing factors alluded to in the sections on CRF and FSH-RF, Mess et al (1967), (1970) also examined the hypothalamic extracts of rats with lesions in various hypothalamic loci for LH-RF content. While FSH-RF content was severely reduced after PVN lesions, LH-RF content was reduced very little. The greatest LH-RF depletion was caused by destruction of the area of the SCH nucleus. These data confirmed previous suspicions that the two pituitary hormones FSH and $\mathrm{LH}$ had two separate and different hypothalamic representations of their respective releasing factors.

Other workers have utilized the recording of multiple unit activity (MUA) in the hypothalamus in the identification of the hypothalamic circuits producing LH-RF. Blake and Sawyer (1972) reported that vaginal and uterine cervix stimulation induced an elevation of MUA in the medial preoptic nuclei of the rat, and that this was not the case in diestrous rats. A brief rise in plasma $\mathrm{LH}$ was observed only after a significant increase in MUA. These findings suggest that the reflex discharge of $\mathrm{LH}$ in the proestrous rat involves preoptic activation of the basal hypothalamus.

Ultrastructural evidence for the localization of the LH-RF area in the $\mathrm{SCH}$ area of the hypothalamus comes from Dr. Montemurro's laboratory. Dr. Robert Clattenburg, has demonstrated that from onehalf hour to one hour post coitum, profound ultrastructural changes occur within certain neurons of this hypothalamic region, Clattenburg, Singh and Montemurro (1972).

While the hypothalamic control of pituitary FSH and LH, respectively, has been considered as being supervised by two separate hypothalamic principles (FSH-RF)-Igarashi and McCann (1964); LH-RF-McCann et al (1960), it has been recently demonstrated that a decapeptide that occurs naturally in the hypothalamus of pigs and has been obtained in a high state of purity is capable of releasing both FSH and LH from the pituitaries of rats, chimpanzees and humans, Schally, Arimura, Kastin, Matsuo, Baba, Redding, Nair and Debuljuk (1971). This has also been demonstrated by in vitro studies with pituitaries from male rats, Matsuo, Baba, Nair, Arimura and Schally (1971) and a synthetic decapeptide with both FSH-RF and LH-RF activities. This finding poses most pressing questions as to the mechanisms of control processes, particularly since at the hypothalamic level the sites of FSH-RF and LH-RF have been shown to be separate, if anatomically closely related areas.

In conclusion, the foregoing data indicate that the hypothalamic region that subserves the control of pituitary $\mathrm{LH}$ is located in the preoptic suprachiasmatic area $(\mathrm{PO}-\mathrm{SCH})$ of the mammalian hypothalamus. It is in turn subject to cyclic control by other parts of the limbic system (Fig. 3).

\section{Hypothalamic Localization of Prolactin Inhibiting Factor (PIF)}

Early evidence for the involvement of the hypothalamus in lactation goes back to the thirties, when 


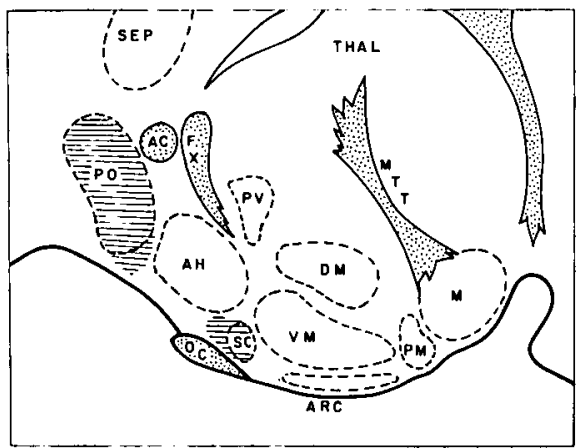

Figure 3-Diagrammatic representation of sagittal section through the hypothalamus. The area included within the horizontal lines is that area which has been implicated in the elaboration of LH-RF. The abbreviations are as in Figure 1.

Hans Selye (1934) noted that lactation in the rat and mouse continues in all glands, even when a limited number of the nipples are suckled. In the glands which are not emptied, involution is much delayed. Selye thought that the suckling stimulus acts through neural impulses on the hypothalamus and then via the stalk on the pituitary. He believed that the response was humoral and consisted in the liberation of Prolactin, the then newly discovered lactation hormone. Selye's concept proved correct and the significance of the suckling stimulus and reflex has remained an important aspect in the study of lactation and its control.

In contrast to all other pituitary hormones, the chronic control of Prolactin or Luteotrophic Hormone (LTH) secretion is inhibitory in male or in cyclic female mammals, including man. Evidence for this "negative" control was first obtained by Desclin (1950) (1956) by transplantation of the hypophysis away from its neural connections, i.e. the ME. More conclusive evidence has come from in vitro studies, when it was demonstrated that the pituitary itself secreted normal amounts of prolactin. However, when hypothalamic tissue was added to the medium, the prolactin-inhibiting activity of the hypothalamus became evident, Pasteels (1961).

The active hypothalamic principle has been designated PIF-Prolactin Inhibiting Factor, Pasteels (1962).
Later, Kragt and Meites (1967) isolated and purified a specific PIF from hypothalamic extract and provided unequivocal proof for its existence. They described a log-dose relationship between prolactininhibiting activity of rat hypothalami and prolactin release by pituitary tissue in vitro. Although this suggests that PIF is a specific hormone, no pure PIF has as yet been prepared. At this time it is still difficult to separate PIF from LH-RF, as shown by the efforts of Dhariwal, Grosvenor, Antunes-Rodrigues and McCann (1968) and the claim to a successful separation by the Schally group, Arimura, Saito, Müller, Bowers, Sawano and Schally (1967).

A delineation of the hypothalamic locus of LTH control has been attempted by many laboratories. In this connection it should be recalled that lactation is the result of two factors: one stimulus causes the secretion of 1) various anterior pituitary hormones that bring about lactogenesis and 2) the posterior lobe hormone oxytocin which initiates milk ejection. Work in the early fifties has demonstrated this rather well by showing that lesions in the supraoptic - paraventricular - hypophyseal tract of lactating rabbits resulted in a failure of milk ejection but not of milk production, Cross and Harris (1952). This was of course the case because the lesions had interrupted oxytocin transport from its formation site in the paraventricuiar nuclei to its storage site in the neural lobe. LTH was not affected by these lesions.

Exploration of the hypothalamus for loci at which various hypophysiotrophic factors are formed have been beset by an everrecurring problem - injury to the ME. This represents a very non-specific interference with hypothalamic function. All hypothalamic factors must pass through the ME where they gain entrance into the primary portal plexus from whence they reach the adenohypophyseal parenchyma. Thus the report that PIF is formed in the ME must be taken with a great deal of caution: lesions in this area are followed by prolonged diestrus and development of large CL McCann and Friedman (1960).

An area somewhat removed from the $\mathrm{ME}$ has been considered a possible candidate for PIF formation. Destructive lesions in the arcuate, VMN and dorsomedial (DMN), and in some experiments, the mammillary nuclei have been shown to result in prolonged diestrus and active CL, Nikitovitch-Winer (1960). Similarly, Quinn and Everett (1967) have reported responsiveness of the VMN-DMN region to selective stimulation, which was followed by pseudopregnancies in rats. This observation gives further evidence for the existence of two separate hypothalamic mechanisms for the control of PIF and LH-RF, since ovulation could not be evoked by stimulation of the aforementioned sites.

As with other hypophysiotrophic principles (see also CRF, FSH-RF, LH-RF) deafferentation studies have been performed in attempts to define the afferent pathways which impinge on the HTA and which are involved in PIF control. Complete deafferentation caused a low and constant plasma LTH level with minimal fluctuations. Anterior deafferentation, on the other hand, was followed by mean increases in LTH levels compared with those in diestrus rats that were serving as controls. Nevertheless, the mean LTH levels were not decreased following complete deafferentation as was LH Weiner, Blake and Sawyer (1972).

In the early seventies it was hypothesized that the hypothalamic control of LTH secretion by the vertebrate pituitary involved both inhibitory factors, Nicoll, Fiorindo, McKenn and Parson (1970) and a stimulating factor. The latter type of factor had previously been demonstrated, but only in birds, Kragt and Meites (1965). Recently, Carlos-Valverde, Chieffo and Reichlin (1972) have shown that porcine and rat hypothalamic tissue also contain a Prolactin Releasing Factor (PRF).

In conclusion, the data presently available suggest that PIF is formed 
in an area covering several hypothalamic nuclei: VMN, DMN and arcuate, and perhaps the area lateral to the PVN as well (Fig. 4).

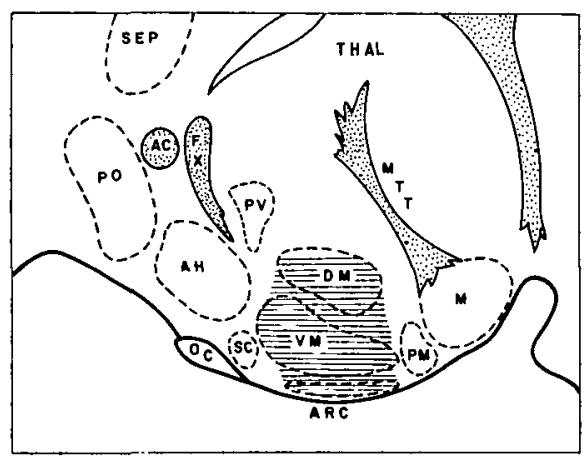

Figure 4-Diagrammatic representation of sagittal section through the hypothalamus. The area included within the horizontal lines is that area which has been implicated in the elaboration of PIF. The abbreviations are as in Figure 1.

\section{Localization of Hypothalamic} Thyrotropin Releasing Factor (TRF)

Although the control of thyroid function by the central nervous system had been suspected over 100 years ago by Charcot (1856), who suggested that Graves' disease was a central nervous system disorder, very little experimental evidence has been forthcoming in the intervening years to implicate the hypothalamus in the control of thyroid function.

In the late thirties Cahane and Cahane (1938) observed that destructive lesions between the optic chiasma and the stalk resulted in histological signs of reduced thyroid function. Thus, many years before the actual demonstration of a hypothalamic principle controlling Thyrotropin Stimulating Hormone (TSH) by Shibusawa, Nishi and Abe (1959), the Cahanes' concept of a "center" in the anterior hypothalamus inducing TSH release was substantiated. The Japanese workers designated the hypothalamic controlling principle "Thyrotropin Releasing Factor" or "TRF."

Greer (1952) was the first to apply modern lesioning technique in attempts to elucidate the hypothalamic control of TSH. While intact rats responded to chronic thiouracil treatment with thyroid hypertrophy, rats with electrolytic lesions in the anterior hypothalamus did not show this effect. The lesions did not depress the response of the thyroid to administered TSH. The responsible area was located on either side of the midline between the PVN and the ME, Greer and Erwin (1954) (1956).

The Greer effect has been questioned by Beugen and van der Werff ten Bosch (1961), who claimed that the "TSH area" in the hypothalamus is necessary only for the maintenance of spontaneous thyroid activity and has no essential role in the regulation of thyroid activity under the usual experimental conditions.

That there exists a difference in thyroid secretion under vesting and "demand" conditions has been demonstrated. Knigge and Bierman (1958) transplanted the pituitary to the cheek pouch of a hypophysectomized hamster and found a maintenance of the slope of the release curve above that of hypophysectomized animals. Nevertheless, these animals were unable to maintain an accelerated thyroid function in response to cold stress. These authors also found that the initial and marked acceleration of release of thyroidal hormone attendant upon exposure of hamsters to cold, is not influenced by adrenal demedullation or decortication. It could however, be inhibited by acute and chronic hypothalamic lesions which, unfortunately, were large and also involved the median eminence.

The present consensus is that the thyroidal cold response is mediated by nervous reflexes acting via the stalk, but the most likely site involved is that associated with temperature regulation, Reichlin (1960). Cooling of the PO-AHA in goats has been reported to be followed by thyroid activation, Andersson, Ekman, Gale and Sundsten (1962), concomitant with the development of hyperthermia. An increased thyroid activity was evidenced by an increase in plasma $\mathrm{PBI}^{131}$ and a corresponding fall in thyroid radioactivity. This effect was blocked two hours after the administration of thyroxin by median eminence lesions, Anderson, Gale and Ohga (1963).
The aforementioned comprehensive study by Mess et al (1967) (1970) (see sections on CRF, FSH-RF, LH-RF) has addressed itself also to a localization of the TRF area. After lesions in the supra - and retrochiasmatic area and the PVN, TRF activity disappeared almost completely from hypothalamic extracts. Considerable reduction was also found after lesions in the area of the VMN and arcuate nuclei. The authors concluded that the area subserving TRF is not as well circumscribed as the areas concerned with FSH-RF and LH-RF synthesis.

Findings from stimulation studies have supplemented those obtained from lesion experiments. Thus, Colfer (1949) reported histological. signs of thyroid hyperactivity following electrical stimulation of the hypothalamus. In the sixties, D'Angelo and Snyder (1963) found a depletion of pituitary stores and an elevated level of circulating TSH following electrical stimulation of several areas in the anterior hypothalamus in rats.

Although it is well established that thyroid hormone acts directly on the pituitary in a "classical" long-loop feedback fashion, the instillation of small amounts of thyroxine into the anterior pituitary inhibits thyroid function at a dose level that is ineffective when injected systemically, Kendall (1962). Thyroxine may act at the hypothalamic level as well. Knigge (1964) found that injection of thyroxine into the POA of the cat markedly depressed thyroid function. The POA is sufficiently removed from the $M E$ so that no thyroxine could "leak" into the portal circulation.

As with other hypophysiotrophic factors, Halasz et al (1965) also investigated the effect of hypothalamic deafferentation on thyroid control. Complete deafferentation of the HTA did not alter thyroid weight and histology and methyluracil treatment of such animals induced goiter, although not to the same degree as in undeafferented animals.

In conclusion, the area involved in TSH-RF formation is a rather large one extending through the anterior 
and medial hypothalamus to include the supraoptic ( $\mathrm{SO}$ ), $\mathrm{SCH}$, arcuate and the VM hypothalamic nuclei (Fig. 5).



Figure 5-Diagrammatic representation of sagittal section through the hypothalamus. The area included within the horizontal lines is that area which has been implicated in the elaboration of TSH-RF. The abbreviations are as in Figure 1.

\section{Hypothalamic Localization of} Growth Hormone-Releasing Factor $(G H-R F)$

The earliest experimental evidence for the participation of the central nervous system in the control of growth and Growth Hormone (GH) secretion comes from Smith (1927) who found poor skeletal growth and disproportionately short tails and thin skin-signs of infantilism-in rats with lesions in the tuber cinereum. The functions of other endocrine glands appeared unaffected as shown by normal thyroid and adrenal weights and estrous cycles.

In the mid-thirties, increased insulin sensitivity was noted in rats with lesions in the PVN-VMN region. This insulin sensitivity, which also occurs in hypophysectomized rats, could be alleviated by GH administration, Cleveland and Davis (1936).

Hetherington and Ranson (1942), using electrolytic lesions to selectively destroy hypothalamic areas, reported that destruction of the medial hypothalamus caused stunting. Lesion experiments by Reichlin (1961) indicated that rats with massive medial lesions that destroyed the ME and the portal plexus had pituitaries with lower GH content (bioassay). Since the portal plexus had been destroyed in these experiments, the results are rather equivocal and could have been due to the cessation of ME function.

In the mid-sixties, linear growth reduction and general microsplanchnia were reported in weanling rats with lesions in the VM hypothalamic nuclei that did not injure the median eminence and thus the primary portal plexus, Bernardis and Skelton (1965) (1967).

The first definitive evidence for the involvement of a hypothalamic locus outside the $\mathrm{ME}$ in the control of Growth Hormone secretion was reported by Bernardis and Frohman (1967) and Frohman and Bernardis (1968). As with the Bernardis and Skelton experiments, the weanling rats in these studies had VMN lesions that did not injure the ME. Both pituitary and plasma growth hormone levels were reduced by even small lesions while larger lesions showed a greater effect on both linear growth and growth hormone levels, Bernardis and Frohman (1970).

Subsequent electrical stimulation studies in various hypothalamic loci in 181 mature rats confirmed the results of the lesion experiments: only stimulation sites located in the VMN, impinging on the arcuate nuclei and the ME, elicited plasma growth hormone rises within five minutes after the onset of stimulation, Bernardis and Frohman (1971). Similarly, Martin (1972) found that plasma Growth Hormone rises in rats after electrical stimulation of the ventromedial nuclei while Toivola and Gale (1972) reported the same results after microinjection of norepinephrine into the VMN.

Although the existence of a hypothalamic principle termed Growth Hormone Releasing Factor (GRF or GH-RF) had been demonstrated by Franz, Haselbach and Libert (1962), only within the last few years has evidence been forthcoming to localize the area where this hypothalamic humor might be formed.

It had been known since the early sixties that the adequate stimulus for Growth Hormone secretion is hypo- glycemia, Roth, Glick, Yalow and Berson (1963). It is confirmatory to the above findings on the localization of GH-RF in the VMN that Pecile, Felici and Mûller (1971) found no Growth Hormone secretion in response to insulin hypoglycemia in the rat when VMN lesions had been placed previously in these animals.

The localization of the GH-RF area in the $\mathrm{VMN}$-arcuate region of the hypothalamus had been suggested years prior to the above findings by the imaginative analyses of the Halasz group at Pecs, Hungary. Transplantation of pituitary fragments into the HTA of hypophysectomized rats resulted in a resumption of growth, although the animals so treated never attained the growth rate of intact animals of the same age Halasz (1964).

Halasz, Schalch and Gorski (1971) also elucidated the effect of deafferentation on growth and GH secretion. Complete deafferentation initially decreased growth only slightly, while partial deafferentation had no consistent effect. Although the pituitary content of $\mathrm{GH}$ was significantly less in the completely deafferented rats than in their controls, the concentration remained unchanged. It was concluded that neural afferents are involved only slightly in maintaining basal $\mathrm{GH}$ secretion and normal body growth, Halasz et al (1971).

As with other hormones, $\mathrm{GH}$ has been shown to have diurnal variations in both pituitary content and plasma levels. Müller, Giustina, Miedico, Pecile, Cocchi and Pozza (1970) reported peaks in pituitary GH concentrations at 1800-0200 hours while plasma $\mathrm{GH}$ exhibited wide fluctuations with peaks at 1800 and 0300 hours. An analysis of hypothalamic GH-RF activity, however, indicated that changes in the latter occurred at different times of the 24 hour cycle and that excursions of GH-RF did not change in phase with pituitary GH rhythm.

In addition to the aforementioned GH-RF Franz et al (1962), Dhariwal, Krulich, Katz and McCann (1965), a Growth Hormone Inhibiting Factor (GIF) has also been postulated, Krulich, Dhariwal, and McCann 
(1968). Recent experiments by Dr. Iwao Nakayama, Dr. Michael Tseng and the author have provided circumstantial evidence that the formation site of the GIF might be located in the DMN. Following destruction of the latter by electrolytic lesions, the pituitary somatotrophs show a depletion of secretory granules as early as 24 hours after the operation. The secretory granules also show a decrease in number, size and mean diameter in comparison with sham-operated controls. Based on previous findings in ACTH secreting cells Nakayama, Nickerson and Skelton (1969) and pituitary somatotrophs in rats bearing a growth hormone-secreting tumor, Nakayama and Nickerson (1973) the authors interpreted their findings as indicating a condition of "oversecretion" or depletion of growth hormone secretory granules. This might be due to a lack of GIF, which is thus likely formed in the dorsomedial hypothalamic area, Nakayama, Tseng and Bernardis (1973).

Recently the Guillemin group at La Jolla has described a peptide"Somatostatin" in ovine hypothalami that both in vivo and in vitro inhibits $\mathrm{GH}$ secretion in rats. The formation site of the 14-amino acid peptide has as yet not been localized, Vale, Brazeau, Rivier, Rivier, Grant, Burgus and Guillemin (1973).

In conclusion, the hypothalamic area controlling growth hormone

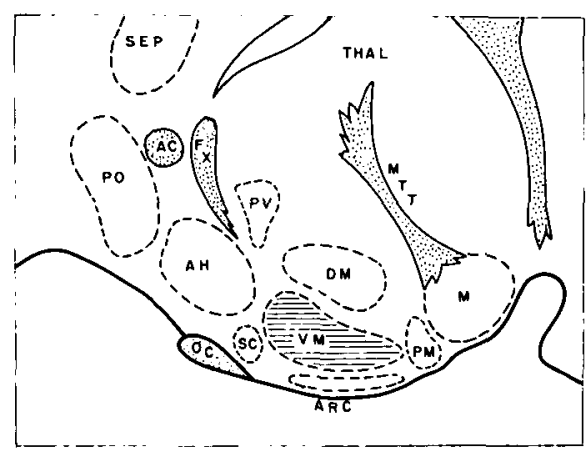

Figure 6-Diagrammatic representation of sagittal section through the hypothalamus. The area included within the horizontal lines is that area which has been implicated in the elaboration of GH-RF. The abbreviations are as in Figure 1. secretion is located in the immediate vicinity of the VMN, in all likelihood, within the nuclei themselves (Fig. 6).

\section{REFERENCES}

ADAMS, J. H., DANIEL, P. M., and PRICHARD, M. M. L. (1965-66). Observations on the portal circulation of the pituitary gland. Neuroendocrinology, 1, 193-213.

ANDERSSON, B., EKMAN, L., GALE, C. C., and SUNDSTEN, J. W. (1962). Activation of the thyroid gland by cooling of the preoptic area in the goat. Acta Physiologica Scandinavica, 54, 191-192.

ANDERSSON, B., GALE, C. C., and OHGA, A. (1963). Suppression by thyroxine of the thyroidal response to local cooling of the "heat loss center." Acta Physiologica Scandinavica, 59, 67-73.

ARIMURA, A., SAITO, T., MULLER, E. E., BOWERS, C. Y., SAWANO, S., and SCHALLY, A. V. (1967). Absence of prolactin release inhibiting activity in highly purified LH-releasing factor. Endocrinology, 80, 972-974.

ASCHNER, B. (1912). Zur Physiologie des Zwischenhirns. Wien Klinische Wochenschrift, 25, 1042-1043.

BERNARDIS, L. L., and SKELTON, F. R. (1965-66). Growth and obesity following ventromedial hypothalmic lesions placed in female rats at four different ages. Neuroendocrinology, 1, 265-275.

BERNARDHS, L. L., and SKELTON, F. R. (1967). Growth and obesity in male rates after placement of ventromedial hypothalamic lesions at four different ages. Journal of Endocrinology, 38, 351-352.

BERNARDIS, L. L., and FROHMAN, L. A. (1967). Plasma and pituitary growth hormone levels in rats with hypothalamic lesions. Endocrinology Society Annual Meeting, p. 86.

BERNARDIS, L. L., and FROHMAN, L. A. (1970). Effect of lesion size in the ventromedial hypothalamus on growth hormone and insulin levels in the weanling rat. Neuroendocrinology, 6, 319-328.

BERNARDIS, L. L., and FROHMAN, L. A. (1971). Plasma growth hormone responses to electrical stimulation of the hypothalamus in the rat. Neuroendocrinology, 7, 193-201.

BEUGEN, V. L., and V. D. WERFFTEN BOSCH (1961). Effects of hypo- thalamic lesions and of cold on thyroid activity in the rat. Acta Endocrinologica (Kobenhavn), 38, 585. 597.

BLAKE, C. A., and SAWYER, C. H. (1972). Effects of vaginal stimulation on hypothalamic unit-activity and pituitary LH release in the rat. Neuroendocrinology, 10, 358-370.

BRODISH, A. (1963). Diffuse hypothalamic system for the regulation of ACTH secretion. Endocrinology, 73, 727-735.

BRODISH, A. (1964). Delayed secretion of $\mathrm{ACTH}$ in rats with hypothalamic lesions. Endocrinology, 74, 28-34.

CAHANE, M., and CAHANE, T. (1938). Sur l'existence des centres nerveux infundibulaires réglant la fonction $\mathrm{du}$ corps thyroide. Acta Medica Scandinavica, 94, 320. 327.

CAJAL, R. (1911). Histologie de systeme nerveux de l'homme et des vertebres. Maloine: Paris.

CARLOS-VALVERDE, R., CHIEFFO, V., and REICHLIN, S. (1972). Prolactin-releasing factor in porcine and rat hypothalamic tissue. Endocrinology, 91, 982-993.

CHARCOT, J. M. (1856). Memoire sur une affection caracterisee par des palpations de coeur et des arteries, le tumefaction de la glande thyroide et une double exopthalmie. Gax de Paris, pp. 38-39.

CLATtENBURG, R. E., SINGH, R. $P$. and MONTEMURRO, D. G. (1972). Post-coital ultrastructural changes in the neurons of the suprachiasmatic nucleus of the rabbit. Zeitschrift für Zellforschung und Mikroskopische Anatomy, 125, 448-459.

CLEVELAND, D., and DAVIS, L. (1936). Further studies on the effect of lesions of the hypothalamus on carbohydrate metabolism. Brain, 59, 459. 465.

COLFER, H. R. (1949). Transcript from American Goitre Association, pp. 376-378. Quoted after Harris, G. W. (1955). The reciprocal relationship between the thyroid and adrenocortical responses to stress. Ciba Foundation Coloquia on Endocrinology, 8, 531-550.

CRITCHLOW, V. (1963). The role of light in the neuroendocrine system. In Advances in Neuroendocrinology, pp. 377-402. Edited by A. A. Nalbandov. University of Illinois Press: Urbana, Ill. 
CROSS, B. A., and HARRIS, B. W. (1952). The role of the neurohypophysis in the milk ejection reflex. Journal of Endocrinology, 8, 148161 .

D'ANGELO, S. A., and SNYDER, J. (1963). Electrical stimulation of the hypothalamus and TSH secretion in the rat. Endocrinology, 73, 75-80.

DeGROOT, J., and HARRIS, G. W. (1950). Hypothalamic control of the anterior pituitary gland and blood lymphocytes. Journal of Physiology (London), 111, 335-346.

DESCLIN, L. (1950). A propos de mecanisme d'action des oestrogens sur la lobe anterieur de l'hypophyse chez le rat. Annals of Endocrinology (Paris), 11, 656-659.

DESCLIN, L. (1956). Hypothalamus et liberation d'hormone luteotrophique. Experiences de greffe hypophysaire chez le rat hypophysectomise. Action lute trophique de l'oxytocine. Annals of Endocrinology (Paris), 17, 586595.

DHARIWAL, A. P. S., KRULICH, L., KATZ, S. H., and McCANN, S. M. (1965). Purification of growth hormone-releasing factor. Endocrinology, 77, 932-936.

DHARIWAL, A. P. S., GROSVENOR, C. E., ANTUNES-RODRIGUES, J., and MCCANN, S. M. (1968). Studies on the purification of ovine prolactininhibiting factor. Endocrinology, 82, 1236-1241.

FLÉRKO, B. (1956). Die Rolle hypothalamischer Strukturen auf die Hemmungswirkung des erhoehten Oestrogenblutspiegels auf die Gonadotrophinsekretion. Acta Biochimica et Biophysica Academiae Scientiarum Hungaricae, Budapest, 9, 17-18.

FLÉRKO, B. (1957a). Einfluss experimenteller Hypothalamuslaesionen auf die durch Follikelhormon indirekt hervorgerufene Hemmung der Luteinisation. Endokrinologie, 34, 202-208.

FLÉRKO, B. (1957b). Le role des structures hypothalamiques dans l'action inhibitrice de la folliculine sur la secretion de l'hormone folliculostimulante. Archives d'Anatomie Microscopique et de Morphologie Experimentale (Paris), 46, 159-172.

FLÉRKO, B., and BARDOS, V. (1956). Eluso hypothalamus sertes hatasa a tuszohormonkezelessel gatolit luteinizaciora. (The effect of the lesion of the anterior hypothalamus on luteinization inhibited by estrogen treatment.) VIIth Meeting of Koranyi
Sandor Society Budapest: MagyarTudomanyos Akademia Biologiai Es Orvosi Tudomanyok Osztalyanak Kozlemenyei 8, 90-93.

FLÉRKO, B., and BARDOS, V. (1961). Absence of compensatory ovarian hypertrophy in rats with anterior hypothalamic lesions. Acta Endocrinologica (Kobenhavn), 36, 180-184.

FORTIER, C. (1952). Studies on the control of ACTH release by means of hypophyseal transplants. Ciba Foundation Colloquia on Endocrinology, 4, 124-138.

FRANZ, J., HASELBACH, C. H., and LIBERT, O. (1962). Studies of the effect of hypothalamic extracts on somatotrophic pituitary function. Acta Endocrinologica (Kobenhavn), 41, 336-350.

FRASCHINI, F., MOTTA, M., and MARTINI, L. (1966). Methods in Drug Evaluation, p. 424. Edited by P. Mantegazza and F. Fraschini. NorthHolland Publishing Company: Amsterdam.

FROHMAN, L. A., and BERNARDIS, L. L. (1968). Growth hormone and insulin levels in weanling rats with ventromedial hypothalamic lesions. Endocrinology, 82, 1125-1132.

GREER, M. A. (1952). Role of the hypothalamus in control of thyroid function. Journal of Clinical Endocrinology, 12, 1259-1268.

GREER, M. A., and ERWIN, H. L. (1954). The location of the hypothalamic area controlling the secretion of thyrotropin by the pituitary. Journal of Clinical Investigation, 33, 939. 949.

GREER, M. A., and ERWIN, H. L. (1956). Evidence of separate hypothalamic centers controlling corticotrophin and thyrotrophin secretion by pituitary. Endocrinology, 58, 665-670.

HALASZ, B. (1964). Neural control of growth hormone secretion. Proceedings of the Second International Congress on Endocrinology, International Congress Service Excerpta Medica Foundation (London), 83, 517-521.

HALASZ, B., and GORSKI, R. A. (1967). Gonadotrophic hormone secretion in female rats after partial or total interruption of neural afferents to the medial basal hypothalamus. Endocrinology, 80, 608-622.

HALASZ, B., PUPP, L., and UHLARIK, S. (1962). Hypophysiotrophic area in the hypothalamus. Journal of Endocrinology, 25, 147-154.
HALASZ, B., PUPP, L., UHLARIK, S., and TIMA, L. (1965). Further studies on the hormone secretion of the anterior pituitary transplanted into the hypophysiotrophic area of the rat hypothalamus. Endocrinology, 77 , 343-355.

HALASZ, B., SCHALCH, D. S., and GORSKI, R. A. (1971). Growth hormone secretion in young rats after partial or total interruption of neural afferents to the medial basal hypothalamus. Endocrinology, 89, 198203.

HALASZ, B., SLUSHER, M. A., and GORSKI, R. A. (1967). Adrenocorticotrophic hormone secretion in rats after partial or total deafferentation of the medial basal hypothalamus. Neuroendocrinology, 2, 43-55.

HARRIS, G. W. (1937). The induction of ovulation in the rabbit, by electrical stimulation of the hypothalamo-hypophysial mechanism. Proceedings of the Royal Society, 122, 374-394.

HARRIS, G. W. (1948). Electrical stimulation of the hypothalamus and the mechanism of neural control of the adenohypophysis. Journal of Physiology (London), 107, 418-429.

HETHERINGTON, A. W., and RANSON, S. W. (1942). The relation of various hypothalamic lesions to adiposity in the rat. Journal of Comparative Neurology, 76, 475-499.

HIROSHIGE, T., and SAKAKURA, M. (1971). Circadian rhythm of corticotropin-releasing activity in the hypothalamus of normal and adrenalectomized rats. Neuroendocrinology, 7, 25-36

HIROSHIGE, T., and SATO, T. (1970). Postnatal development of circadian rhythm of corticotropin-releasing activity in the rat hypothalamus. Endocrinologia Japonica, 17, 1-6.

HOHLWEG, W., and JUNKMANN, K. (1932). Die hormonal-nervoese Regulierung der Funktion des $\mathrm{Hy}$ pophysenvorderlapens. Klinische Wochenschrift, 11, 321-323.

IGARASHI, M., and McCANN, S. M. (1964). A hypothalamic follicle stimulating hormone releasing factor. Endocrinology, 74, 446-452.

KENDALL, J. W. (1962). Studies on inhibition of corticotropin and thyrotropin release utilizing microinjections into the pituitary. Endocrinology, 71, $452-455$.

KNIGGE, K. M. (1964). Regulation of TSH release, neural regulation of TSH secretion; effect of diencephalic 
lesions and intracerebral injection of thyroxin and thyrotropin upon thyroid activity in the cat. In Major Problems in Neuroendocrinology, pp. 261-285. Edited by E. Bajusz and G. Jasmin. Karger Verlag: Basel, New York.

KNIGGE, K. M., and BIERMAN, S. M. (1958). Evidence of central nervous system influence upon coldinduced acceleration of thyroidal $\mathrm{I}^{\mathbf{1 3 1}}$ release. American Journal of Physiology, 192, 625-632.

KOVES, K., and HALASZ, B. (1970). Location of the neural structures triggering ovulation in the rat. Neuroendocrinology, 6, 180-193.

KRAGT, C. L., and MEITES, J. (1965). Stimulation of pigeon pituitary prolactin release by pigeon hypothalamic extract in vitro. Endocrinology, 76, 1169-1176.

KRAGT, C. L., and MEITES, J. (1967). Dose response relationships between hypothalamic PIF and prolactin release by rat pituitary tissue in vitro. Endocrinology, 80, 1170-1176.

KRULICH, L., DHARIWAL, A. P., and McCANN, S. M. (1968). Stimulatory and inhibitory effects of purified hypothalamic extracts on growth hormone release from rat pituitary in vitro. Endocrinology, 83, 783790.

McCANN, S. M., and FRIEDMAN, H. M. (1960). The effect of hypothalamic lesions on the secretion of luteotrophin. Endocrinology, 67, 597608.

MCCANN, S. M., TALEISNIK, S., and FRIEDMAN, H. M. (1960). LHreleasing activity in hypothalamic extracts. Proceedings of the Society of Experimental Biology and Medicine (New York), 105, 432-434.

MARSHALL, F. H. A. (1936). Sexual periodicity and the causes which determine it. The Croonian Lecture, Philosophical Transactions of the Royal Society of London; B: Biological Sciences, 226, 423-456.

MARTIN, J. B. (1972). Plasma growth hormone $(\mathrm{GH})$ response to hypothalamic or extrahypothalamic electrical stimulation. Endocrinology, 91, 107115.

MATSUO, H., BABA, Y., NAIR, R. M. G., ARIMURA, A., and SCHALLY, A. V. (1971). Chemical structure of the porcine $\mathrm{LH}$ - and FSH-releasing hormone. I. The proposed amino acid sequence. Biochemical and Biophysical Research Communications, 43, 1334-1339.
MESS, B., FRASCHINI, F., MOTTA, M., and MARTINI, L. (1967). The topography of the neurons synthesizing the hypothalamic releasing factors. Second International Symposium on Steroid Hormones No. 132, pp. 1004-1013. Edited by L. Martini. Excerpta Medica Foundation: Amsterdam.

MESS, B., ZANISI, M., and TIMA, L. (1970). Site of production of releasing and inhibiting factors. In The Hypothalamus, pp. 259-276. Edited by L. Martini, M. Motta, and F. Fraschini, Academic Press: New York and London.

MOBERG, G. P., SCAPAGNINI, U., DeGROOT, J., and GANONG, W. G. (1971). Effect of sectioning the fornix on diurnal fluctuation in plasma corticosterone levels in the rat. Neuroendocrinology, 7, 11-15.

MÜLLER, E. E., GIUSTINA, G., MIEDICO, D., PECILE, A., COCCHI, D., and POZZA, G. (1970). Circadian pattern of bioassayable and radioimmunoassayable growth hormone in the pituitary of female rats. Proceedings of the Society for Experimental Biology and Medicine (New York), 135, 934-939.

NAKAYAMA, I., and NICKERSON, P. A. (1973). Suppression of anterior pituitary in rats bearing a transplantable growth hormone and prolactin secreting tumor (MtTO-W10). Endocrinology, 92, 516-524.

NAKAYAMA, I., NICKERSON, P. A., and SKELTON, F. R. (1969). An ultrastructural study of the adrenocorticotrophic hormone secreting cell in the rat adenohypophysis during adrenal cortical regeneration. Laboratory Investigation, 21, 169-178.

NAKAYAMA, I., TSENG, M. T., and BERNARDIS, L. L. (1973). Ultrastructural evidence for possible localization of growth hormone inhibiting factor (GIF) in dorsomedial hypothalamus. Federal Proceedings, 32, Abstract No. 293.

NICOLL, C. S., FIORINDO, R. P., McKENNEE, C. T., and PARSON, J. A. (1970). In Hypophysiotropic Hormones of the Hypothalamus, Assay and Chemistry, p. 115. Edited by J. Meites. Williams and Wilkins Company: Baltimore.

NIKITOVITCH-WINER, M. D. (1960). The influence of the hypothalamus on luteotrophin secretion. Memoirs of the Society for Endocrinology, 9, 70-72.
NIKITOVITCH-WINER, M. D. (1962). Induction of ovulation in rats by direct intrapituitary infusion of median eminence extracts. Endocrinology, 70, 350-358.

PASTEELS, J. L. (1961). Secretion de prolactine par l'hypophyse on culture de tissus. Comptes Rendus Heldom adaires des Seances de l'Academie des Seiences (Paris), 253, 2140-2142.

PASTEELS, J. L. (1962). Administration d'extraits hypothalamiques a 18 hypophyse de rat in vitro, dans le but D8 controller le secretion de prolactine. Comptes Rendus Heldom adaires des Seances de l'Academie des Sciences (Paris), 254, 2664-2666.

PECILE, A., FELICI, M., and MÜLLER, E. E. (1971). Growth hormone releasing (GRF) activity in rats submitted to electrolytic lesions of the ventromedial nuclei (VMN) or of the posterior nuclei (PH) of the hypothalamus. Naunyn-Schmiedeberg's Archives of Pharmacology (Berlin), 269, 407-408.

QUINN, D. L., and EVERETT, J. W. (1967). Delayed pseudopregnancy induced by selective hypothalamic stimulation. Endocrinology, 80, 155-162.

REICHLIN, S. (1960). Thyroid function, body temperature regulation and growth in rats with hypothalamic lesions. Endocrinology, 66, 340-354.

REICHLIN, S. (1961). Growth Hormone (GH) content of pituitaries in rats with hypothalamic lesions. Endocrinology, 69, 225-231.

ROTH, J. GLICK, S. M., YALOW, R. S. S., and BERSON, S. A. (1963). Hypoglycemia: A potent stimulus to secretion of growth hormone. Science, $140,987-988$.

SAFFRAN, M., and SCHALLY, A. V. (1955). Release of corticotrophin by anterior pituitary tissue in vitro. Canadian Journal of Biochemistry, 33, 408-415.

SAWYER, C. H. (1959). Effects of brain lesions on estrous behavior and reflexogeneous ovulation in the rabbit. Journal of Experimental Zoology, 132, 227-246.

SCHALLY, A. V., ARIMURA, A., KASTIN, A. J., MATSUO, H., BABA, Y., REDDING, T., NAIR, R. M. G., and DEBELJUK, L. (1971). Gonadotropin-releasing hormone: one polypeptide regulates secretion of luteinizing and folliclestimulating hormones. Science, 173, 1036-1038. 
SEIDEN, G., and BRODISH, A. (1971). Physiological evidence for "short loop" feedback effects of ACTH on hypothalamic CRF. Neuroendocrinology, 8, 154-164.

SEIDEN, G., and BRODISH, A. (1972). Persistence of a diurnal rhythm in hypothalamic corticotrophin-releasing factor (CRF) in the absence of hormonal feedback. Endocrinology, 90, 1401-1403.

SELYE, H. (1934). On the nervous control of lactation. American Journal of Physiology, 107, 535-538.

SHIBUSAWA, K., NISHI, K., and ABE, C. (1959). Further observations on the hypothalamic control of the thyroid gland. Endocrinologia Japonica, 6, 31-46.
SMITH, P. E. (1927). The disabilities caused by hypophysectomy and their repair. Journal of the American Medical Association, 88, 158-161.

SZENTÁGOTHAI, J., FLÉRKO, B., MESS, B., and HALÁSZ, B. (1968). Hypothalamic control of the anterior pituitary. Akadémiai Kiadò, Budapest.

TOIVOLA, P. T. K., and GALE, C. C. (1972). Stimulation of growth hormone by micro injection of norepinephrine into the hypothalamus of baboons. Endocrinology, 90, 895902.

VALE, W., BRAZEAU, P., RIVIER, C., RIVIER, J., GRANT, C.,
BURGUS, R., and GUILLEMIN, R. (1973). Inhibitory hypophysiotropic activities of hypothalamic somatostatin. Federal Proceedings, 32, 211, Abstract No. 2.

WEINER, R. I., BLAKE, C. A., and SAWYER, C. H. (1972). Integrated levels of plasma $\mathrm{LH}$ and prolactin following hypothalamic deafferentation in the rat. Neuroendocrinology, 10, 349-357.

ZANISI, M., and MARTINI, L. (1969). Effect of brain implants of cycloheximide on hypothalamic follicle stimulating hormone releasing factor (FSHRF) and on pituitary FSH. Program 51st Meeting Endocrine Society, p. 202, Paper No. 343. 